\title{
Evaluation of WARM Model for Simulating Some Rice Varieties in Northern Delta
}

\author{
Shimaa A. Badawy 1
}

\begin{abstract}
The present research study was carried out in Milan University, Italy during 2013 to simulate rice yield by using WARM simulation model. Research on rice cropping systems carried out in Egypt has to face the great climate changes, and the linked abundance of cultivated varieties, characteristic of the high latitudes-temperate areas where rice is traditionally grown. Therefore, dynamic simulation models can provide a useful tool for system analysis needed to improve the knowledge, the agronomic management and crop monitoring.
\end{abstract}

WARM (Water Accounting Rice Model) simulates yield of paddy rice (Oryza sativa $\mathrm{L}$.), based on temperaturedriven development and radiation-driven crop growth. It also simulates; biomass partitioning, floodwater effect on temperature, spikelet sterility, floodwater and chemicals management, and soil hydrology. Biomass estimates from WARM were evaluated. The test-area was Sakah Kaferelsheikh (Egypt). Data collected from 2003 to 2012 from rice crop grown under flooded and non-limiting conditions were split into a calibration (to estimate WARM model parameters) and an evaluation sets. Plants were sampled during the life cycle from rice plots of two rice cultivars Sakha 101 and Giza 177, maintained at potential production, to determine some important crop variables and parameters such as aboveground biomass (AGB), leaf area index (LAI), potential yield, specific leaf area, and the date of the main phonological stages.

Results show that the model was able to simulate rice growth for both varieties. The assessment of model performances has shown average of relative root mean square error (RRMSE) calculated on AGB curves was above $50 \%$ for the calibration and $30 \%$ for evaluation sets. The modelling efficiency (EF) is always positive and the coefficient of determination (CD) is always very close to 1 .

Indeed, intercept and slope were always close to their optima and $\left(\mathbf{R}^{2}\right)$ was always higher than 0.90 . The indices of agreement calculated for the evaluation datasets were better than the corresponding ones computed at the end of the calibration, indirectly proving the robustness of the modeling approach. WARM's robustness and accuracy, combined with the low requirements in terms of inputs and the implementation of modules for reproducing biophysical processes strongly influencing the year-to-year yield variation, make the model suitable for forecasting rice yields on regional, national and international scales.

Key words: WARM, Oryza sativa L., simulation model, flooded conditions, yield forecast, climate change

\footnotetext{
${ }^{1}$ Department of Agronomy, faculty of agriculture,

Kafrelsheikh University

Received November 9, 2013, Accepted December 25, 2013
}

\section{INTRODUCTION}

Rice (Oryza sativa L.), the staple food of about onehalf of the world population, providing $35-60 \%$ of the dietary calories consumed by 3 billion people, is arguably among the most important crops worldwide. Although total rice production has more than doubled since 1965, problems about food security still persist and need to be managed based on early and reliable forecasting activities. (Cassman et al., 1997), so that it appears crucial to increase rice production through an increase in yield from rice-cultivated land because an expansion of irrigated areas probably will not be realizable (Mae, 1997).

Rice is one of the major field crops in Egypt. It occupies about 0.65 million hectares, produces approximately 6 million metric tons of rough rice annually (RRTC, 2005) and contributes about $20 \%$ to the per capita cereal consumption. The country ranks as one of the highest in the world in terms of productivity per unit area.

Modern rice-culture, facing both food and environmental security, requires sustainable and environmentally sound management analysis, both at farm and regional scale, integrating our knowledge of pedoclimatic conditions, crop production physiology, and agrotechniques for analyzing agro-ecosystem. Dynamic simulation models could provide the technical support for analyzing system for better planning, management, and monitoring.

Crop modelling has had a lot of appeal over the years, driven as much by the community's expectations as by the targets identified by modelers (Day, 2001). Since the 1980s, crop modellers have been pointing their attention on rice productions (e.g. Bachelet and Gay, 1993; Mahmood, 1998; Confalonieri and Bocchi, 2005; Confalonieri et al., 2006a). Egypt is the largest rice producer, with more than half of the total production. In Egypt, the crop is typically grown in flooded fields, also to achieve thermal regulation. This and other typical features of rice systems (e.g. weed and disease management, nutrient cycles) make it a challenge to simulate rice growth via a generic crop simulator.

WARM (Confalonieri et al., 2006b) is a novel model for paddy rice simulations developed by an 
interdisciplinary network of scientists working in different fields of rice research and modelling (http://mars.jrc.it/mars/Projects/WARM). Compared to the rice models already available (e.g. CERES-Rice, Singh et al., 1993; ORYZA, Kropff et al., 1994; CRISP, Anastacio et al., 1999), WARM takes into account some relevant processes influencing the final yield usually not considered (i.e. micrometeorological peculiarities of paddy fields, diseases, hydrology of paddy soils, coldshocks induced spikelet sterility) and reproduces the biophysical processes with a consistent level of complexity. That is, the same variable is never affected by processes modelled in a very detailed way and others which are reproduced using rough approaches. Moreover, the number of input parameters is very low and none of the parameters is without a biophysical meaning (i.e. impossible to measure or estimate from measurements), thus facilitating model parameterization and use. Moreover, all parameters describing cultivar morphological and physiological features have a biophysical meaning and can be directly measured or derived from measured data. The peculiarity of a ricebased cropping system was analyzed and led to specific modules for the simulation of the floodwater effect on the vertical thermal profile (Confalonieri et al., 2005), the simulation of blast disease, the simulation of the typical hydrology of paddy soils and the simulation of the yield losses due to cold shocks during the preflowering period. The model has proven to be suitable and robust for small-scale simulations, where information for parameterizing and feeding models is characterized by a high degree of uncertainty (Wit et al., 2005).

Therefore, the objective of this work was to calibrate and evaluate WARM model for Japonica type early (JE) and Japonica type medium-late (JM) varieties, to enable us to forecast yield and to assess the likely impact of climate change on grain yield and yield variability.

\section{MATERIALIS AND METHODS}

\section{Experimental data}

This research was carried out in Milan University, Italy during the year 2013 to simulate rice yield through the WARM simulation model developed by the crop modeller Prof. Roberto Confalonieri (Department of Crop Science, Section of Agronomy, University of Milan).

The data of the WARM simulation model were collected from the experimental results carried out in the Rice Research experimental farm at Sakha Reseach station and published in the Rice Annual report from 2003 up to 2012 as well as the data of phenology and physiology characters recorded for variety registration of Giza 177 and Sakha 101. Daily meteorological data between 2003 and 2012 (rain fall, maximum and minimum air temperature and global solar radiation) were collected from Kafrelsheikh automatic weather stations related to weather central lab- Agriculture Research Center (ARC) , the soils were sub-acid, with medium-low cation exchange capacity (CEC). Plant samples were dried in oven until constant weight to determine the dry matter weight of aboveground biomass (AGB) which will be always expressed as dry matter in this text, leaf area index (LAI) was obtained by measuring the area of leaves with a leaf area meter and specific leaf area (SLA) by dividing leaves area by leaves weight. For all experiments the soils were characterized by medium nutrients availability, the harvest index (HI) and the phenological stages of emergence, flowering and maturity [respectively codes 10,65 and 89 of the Biologische Bundesanstalt, Bundessortenamt and CHemical industry. (BBCH) scale for rice] were determined (Lancashire et al.,1991).

In all experiments, the plots were kept weed free and plant protection was applied as necessary to avoid the presence of pests and diseases. The sowing date was 15 May (the day136 of year), rice was direct-seeded and the field was flooded. In the experiments, where different $\mathrm{N}$ levels were applied, the plots fertilized with the amount of $\mathrm{N}$ were considered for this study was conducted under non-limiting conditions.

Chemical and physical soil analyses were performed at the beginning of each experiment to determine texture and organic matter. In all trials, crop samples were taken during the growing season to determine $A G B$. Harvest index $(H I)$ was computed at harvest time.

\begin{tabular}{|c|c|c|c|c|c|c|c|c|}
\hline $\begin{array}{l}\text { Experimental } \\
\text { site }\end{array}$ & $\begin{array}{c}\text { Latitude } \\
\mathbf{N}\end{array}$ & $\begin{array}{c}\text { Longitude } \\
\text { E }\end{array}$ & $\begin{array}{c}\text { Soil } \\
\text { texture }\end{array}$ & $\begin{array}{c}\text { Sowing } \\
\text { date }\end{array}$ & Variety & $\begin{array}{l}\text { Variety } \\
\text { group }\end{array}$ & $\begin{array}{c}\text { Measured } \\
\text { variables }\end{array}$ & $\begin{array}{c}\text { Nitrogen } \\
\text { treatment }\end{array}$ \\
\hline Sakha, & $31^{\circ} 57^{-}$ & $30^{\circ} 57$ & clay & 15 May & Giza 177 & $\mathrm{JE}$ & $\begin{array}{l}\text { AGB*, } \\
\mathrm{LAI}^{* * *}\end{array}$ & $\begin{array}{c}\text { As } \\
\text { recommended }\end{array}$ \\
\hline $\begin{array}{l}\text { Kafrelsheikh } \\
\text { Egypt }\end{array}$ & & & & 15 May & Sakha 101 & $\mathrm{JM}$ & $\begin{array}{c}\text { Potential } \\
\text { yield }\end{array}$ & \\
\hline
\end{tabular}


Plant $\mathrm{N}$ concentration $(P N C)$ was measured in samples taken at the same dates when $A G B$ was determined.

\subsection{Crop growth simulation}

In this study, the WARM approach for the simulation of rice growth under potential conditions was evaluated.

In the following section, a description of the main WARM peculiarities is given. Table (2) shows the main approaches for crop growth and development implemented in WARM.

For crop development, the thermal time accumulated between a base temperature and a cut-off temperature is computed. The accumulated thermal time can be optionally corrected with a factor accounting for photoperiod. Base and cut-off temperatures can be set to different values for the periods sowing - emergence and emergence - physiological maturity.

Similar to SUCROS-derived models, development stages are standardized by converting growing degreedays $(G D D s)$ into a numerical code $(D V S)$ from 0.00 to 2.00 (respectively, emergence and physiological maturity, with $D V S=1.00$ corresponding to flowering), useful for synchronizing the simulation of different processes. There variables are obtained as follows (Eqs. $(1,2))$, respectively, for the periods emergenceflowering and flowering-physiological maturity (Confalonieri et al., 2009):

$$
\begin{aligned}
& D V S=\frac{(\text { GDDcum }- \text { GDDem })}{\text { GDDflo }} \\
& D V S=\frac{1+(\text { GDDcum }- \text { GDDem }- \text { GDDflo })}{\text { GDDmat }}
\end{aligned}
$$

Where: GDDcum $\left({ }^{\circ} \mathrm{C}\right.$-day $)=$ the cumulated $G D D s$,

GDDem $\left({ }^{\circ} \mathrm{C}\right.$-day $)=$ the $G D D s$ required to reach emergence,

$G D D f$ lo $\left({ }^{\circ} \mathrm{C}\right.$-day $)=$ the $G D D s$ required to reach flowering,

GDDmat $\left({ }^{\circ} \mathrm{C}\right.$-day $)=$ the $G D D s$ required to reach physiological maturity.

\section{WARM: a novel model for rice simulation}

Temperature is one of the most important driving variables for simulation of crop growth and development. In paddy rice systems, this meteorological variable is greatly influenced by the presence of floodwater. In WARM, the micrometeorological model TRIS proposed by Confalonieri et al. (2005) is adopted to take into account the floodwater effect on the vertical thermal profile. TRIS generates hourly and daily temperatures for both the water body and the air layers above the air-water interface (18 layers of $0.1 \mathrm{~m}$ each).
In particular, the temperatures generated by TRIS at the meristematic apex height are used for simulating the processes related to plant development and spikelet sterility. Average canopy temperature is used for simulating thermal limitation to photosynthesis and leaves aging.

For the simulation of $A G B$ accumulation and partitioning, and $L A I$ development, the GAIA model (Confalonieri, 2005) is used. The net photosynthesis rate is simulated using a $R U E$-based approach accounting for the effect of temperature limitations, saturation of the enzymatic chains, and senescence phenomena on radiation use efficiency (Confalonieri et al., 2006b). $A G B$ accumulated each day is assigned to leaves using a parabolic function which assumes the maximum value (input parameter RipLO) at emergence and zero at flowering. $A G B$ partitioning to panicles starts at the panicle initiation stage $(P I)$ and is assumed as maximum at the beginning of the ripening phase, when all the daily accumulated $A G B$ is partitioned to panicles. Stems biomass is computed by subtracting panicles and leaves biomasses from total $A G B$.

\section{Model parameterization and validation}

WARM model version 1.9.6 (9 August 2007) was used. Options were set to avoid limitations due to water and nutrients stresses, pests and diseases. Under such potential conditions, the parameterization was mostly based on previous research, field measurements, and reference values from the user guide supplied with the models. For some parameters, a calibration work was performed on a sub-set of $A G B$ data and varied between Japonica-type, medium-late maturity varieties (JM) and Japonica early maturity -type varieties (JE).

WARM parameters mostly affecting the AGB at physiological maturity. Such relevant parameters were either calibrated or determined from direct field measurements. All other parameters were left to default. Information about parameters and their sources of information are shown in Table (3).

Maximum radiation use efficiency (maximum $R U E$ ) was set for WARM to the values measured by Boschetti et al. (2006) on the same varieties. These values, higher than those published for rice and other C3 species from some authors (e.g. Kiniry et al., 1989) and were similar with those reported by Campbell et al. (2001). Specific leaf area (SLA) values were derived by Boschetti et al. (2006) for the same groups of varieties. The agreement between observed and predicted values was expressed by using the indices proposed by Loague and Green (1991): the relative root mean squared error 
Table 2. Approaches to the simulation of crop growth and development implemented by WARM.

\begin{tabular}{ll}
\hline Process & WARM \\
\hline -Development & -Thermal time accumulation, possibly accounting for photoperiod \\
-Daily biomass accumulation & -Net photosynthesis, based on radiation use efficiency \\
-Factors limiting biomass accumulation & -Air temperature, saturation of the enzymatic chains, senescence, \\
& diseases \\
-Leaf area development & -Derived from leaf biomass and a daily calculated specific leaf area \\
& (the latter derived from development stage and two input \\
-Floodwater effect on temperatures & parameters: specific leaf area at emergence and at mid-tillering) \\
& -Mechanistic micrometeorological approach (resolution of surface \\
-Extreme weather events' effects & energy balance equations)
\end{tabular}

Table 3. WARM parameters (C: calibrated parameters; L: literature; E: local experience; M: measured; D: WARM default parameter). JM: Japonica-type varieties (medium maturity); JE: japonica-type (early maturity) varieties. GDD: growing degree days. AGB: aboveground biomass

\begin{tabular}{|c|c|c|c|c|c|}
\hline \multirow[t]{2}{*}{ Parameter } & \multirow[t]{2}{*}{ Units } & \multicolumn{2}{|c|}{ Value } & \multirow[t]{2}{*}{ Description } & \multirow[t]{2}{*}{ Determination } \\
\hline & & $\mathbf{J M}$ & JE & & \\
\hline \multicolumn{6}{|l|}{ Development } \\
\hline TbaseDem & ${ }^{\circ} \mathrm{C}$ & 25 & 25 & $\begin{array}{l}\text { Base temperature for development before } \\
\text { emergence }\end{array}$ & $\mathrm{E}, \mathrm{L}$ \\
\hline TmaxDem & ${ }^{\circ} \mathrm{C}$ & 38 & 38 & $\begin{array}{l}\text { Maximum temperature for development } \\
\text { before emergence }\end{array}$ & $\mathrm{E}$ \\
\hline GDDem & ${ }^{\circ} \mathrm{C}$-days & 170 & 145 & GDDs from sowing to emergence & $\mathrm{M}$ \\
\hline TbaseD & ${ }^{\circ} \mathrm{C}$ & 25 & 25 & $\begin{array}{l}\text { Base temperature for development before } \\
\text { emergence }\end{array}$ & $\mathrm{L}$ \\
\hline $\operatorname{TmaxD}$ & ${ }^{\circ} \mathrm{C}$-days & 38 & 38 & $\begin{array}{l}\text { Maximum temperature for development } \\
\text { before emergence }\end{array}$ & $\mathrm{L}$ \\
\hline GDDem-fl & ${ }^{\circ} \mathrm{C}$-days & 3130 & 2540 & GDDs from emergence to flowering & M \\
\hline GDDfl-mat & ${ }^{\circ} \mathrm{C}$-days & 695 & 740 & GDDs from flowering to maturity & M \\
\hline GDDmat-harv & & 195 & 200 & GDDs from maturity to harvest & \\
\hline Growth & $\mathrm{gMJ}^{-1}$ & & & & $\mathrm{~L}$ \\
\hline RUE $^{\mathrm{a}}$ & - & 2.6 & 2.3 & Radiation use efficiency & $\mathrm{C}$ \\
\hline K & ${ }^{\circ} \mathrm{C}$ & 0.50 & 0.50 & Extinction coefficient for solar radiation & $\mathrm{E}, \mathrm{C}$ \\
\hline TbaseG & ${ }^{\circ} \mathrm{C}$ & 12 & 12 & Base temperature for growth & $\mathrm{E}, \mathrm{C}$ \\
\hline ToptGa & ${ }^{\circ} \mathrm{C}$ & 28 & 28 & Optimum temperature for growth & $\mathrm{E}$ \\
\hline TmaxG & $\begin{array}{l}\mathrm{m}^{2} \mathrm{~m}^{-2} \\
\mathrm{~m}^{2} \mathrm{~kg}^{-1}\end{array}$ & 30 & 30 & Maximum temperature for growth & \\
\hline LAIini & $\mathrm{m}^{2} \mathrm{~kg}^{-1}$ & 0.02 & 0.02 & Initial leaf area index & $\mathrm{D}, \mathrm{C}$ \\
\hline SLAini & - & 29 & 29 & Specific leaf area at emergence & M \\
\hline SLAtill & ${ }^{\circ} \mathrm{C}$-days & 18 & 18 & Specific leaf area end tillering & M \\
\hline RipL0a & $\mathrm{Cm}$ & 0.8 & 0.8 & $A G B$ partition to leaves at emergence & $\mathrm{C}$ \\
\hline LeafLife & - & 700 & 710 & Leaf duration & $\mathrm{C}$ \\
\hline ApexHeight & & 100 & 105 & Maximum panicle height & $\mathrm{E}$ \\
\hline $\mathrm{Kc}$ & & 1.05 & 1.05 & Crop coefficient at full canopy & $\mathrm{L}$ \\
\hline
\end{tabular}

${ }^{a}$ Relevant parameters from the sensitivity analysis (Confalonieri et al., 2006b). 
(RRMSE, minimum and optimum $=0 \%$ ), the coefficient of determination $(\mathrm{CD}$, minimum $=0$, optimum $=1$, indicates whether the model reproduces the trend of measured values or not), the modelling efficiency (EF, $-\infty /+\infty$, optimum $=1$, if positive, indicates that the model is a better predictor than the average of measured values), the coefficient of residual mass (CRM, 0-1, optimum $=0$, if positive indicates model underestimation) and the parameters of the linear regression equation between observed and predicted values.

\section{RESULTS AND DISCUSSION}

The main purpose of this study was to evaluate the adequacy of the WARM model for simulating rice crop in Egypt, to help us to forecast yield and to assess the likely impact of climate change on grain yield and yield variability. The data used, collected under optimal conditions for water and nitrogen availability, were split into two independent datasets for the calibration and evaluation activities.

\subsection{Calibration of crop model parameters}

Warm parameter values (development and growth parameters) with the source of information or after calibration are shown in Table (3). Base and optimum temperatures are in the range of those reported, respectively, by Sié et al. (1998) and Casanova et al. (1998). Maximum temperatures are coherent with those used by Mall and Aggarwal (2002) for the CERES-Rice and ORYZA1 models.

For radiation use efficiency (RUE) measured values were derived from Bouman et al. (2006) and Boschetti et al. (2006) for the same group of varieties. The value of 0.5 for Extinction coefficient for solar radiation (k) is consistent with that reported by (Dingkuhn et al., 1999). The values of Specific leaf area at emergence (SLAini) and Specific leaf area end tillering (SLAtill) are within the range of those measured by Dingkuhn et al. (1998) and by Boschetti et al. (2006). SLAtill and LeafLife (Leaf duration) were calibrated to allow the model to reproduce measured leaf area index curves.

Air temperature is in fact one of the most important driving variables in crop models and, in paddy fields, it is strongly influenced by floodwater. Nishiyama (1995) indicated water warming as effective up to several centimeters above the water surface. Other authors (Dingkuhn et al., 1995) underlined that, in paddy fields. In fact, the meristematic apex is exposed to water temperature until the panicle initiation stage; then, internodes elongation lifts the apex out of the water surface (Dingkuhn et al., 1995). Such effects are accounted for by WARM through the specialized micrometeorological module TRIS.

There was general agreement between observed and simulated aboveground biomass (AGB t/ha), leaf area

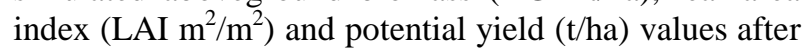
calibration for both varieties as shown in Figures $(1,2)$ and Table (4).

In general, WARM presents a reasonable accuracy in simulating aboveground biomass accumulation and leaf area index for both varieties Giza 177 and Sakha 101, respectively. This is confirmed by the fitting indices as shown in Table (4) where the coefficient of residual mass is negative for the two datasets. While the relative root mean square error values obtained for both varieties are above $20 \%$, the others, though presenting satisfying results, are slightly higher. The same considerations are valid for the modeling efficiency. In general, the regression parameters are satisfactory: slope values are close to one for all simulations.

Simulated values of aboveground biomass for both varieties present a good agreement with measured ones in almost all the situations, with the modeling efficiency constantly above 0.9 . The agreement between observed and simulated leaf area index values is usually lower. This is probably due both to the difficulty of simulating the balance between emission and death of green leaf area index units before flowering and to the higher errors in leaf area index measurements compared with aboveground biomass ones. (Confalonieri et al., 2009).

Although the daily aboveground biomass accumulation rate depends on absorbed radiation and therefore on green leaf area index state, the not completely satisfactory simulation of green leaf area index before flowering does not significantly affect aboveground biomass accumulation, because in that phase the canopy is practically closed and the interception of radiation can be considered complete as mentioned by (Confalonieri et al., 2009).

Calibrated values for these parameters are within the range of values found in the literature and allowed the model to reproduce measured data in a satisfactory way, especially the aboveground biomass curves.

The predicted potential yields for both varieties were similar to observed yields after calibration. Since, the statistical analysis showed a reasonable agreement between observed and predicted potential yield, with indices of agreement RRMSE values ranging between 33\% and 39\% for Giza 177 and Sakha 101, respectively and $\mathrm{EF}$ and $\mathrm{CD}$ was always close to one, Table (4). 

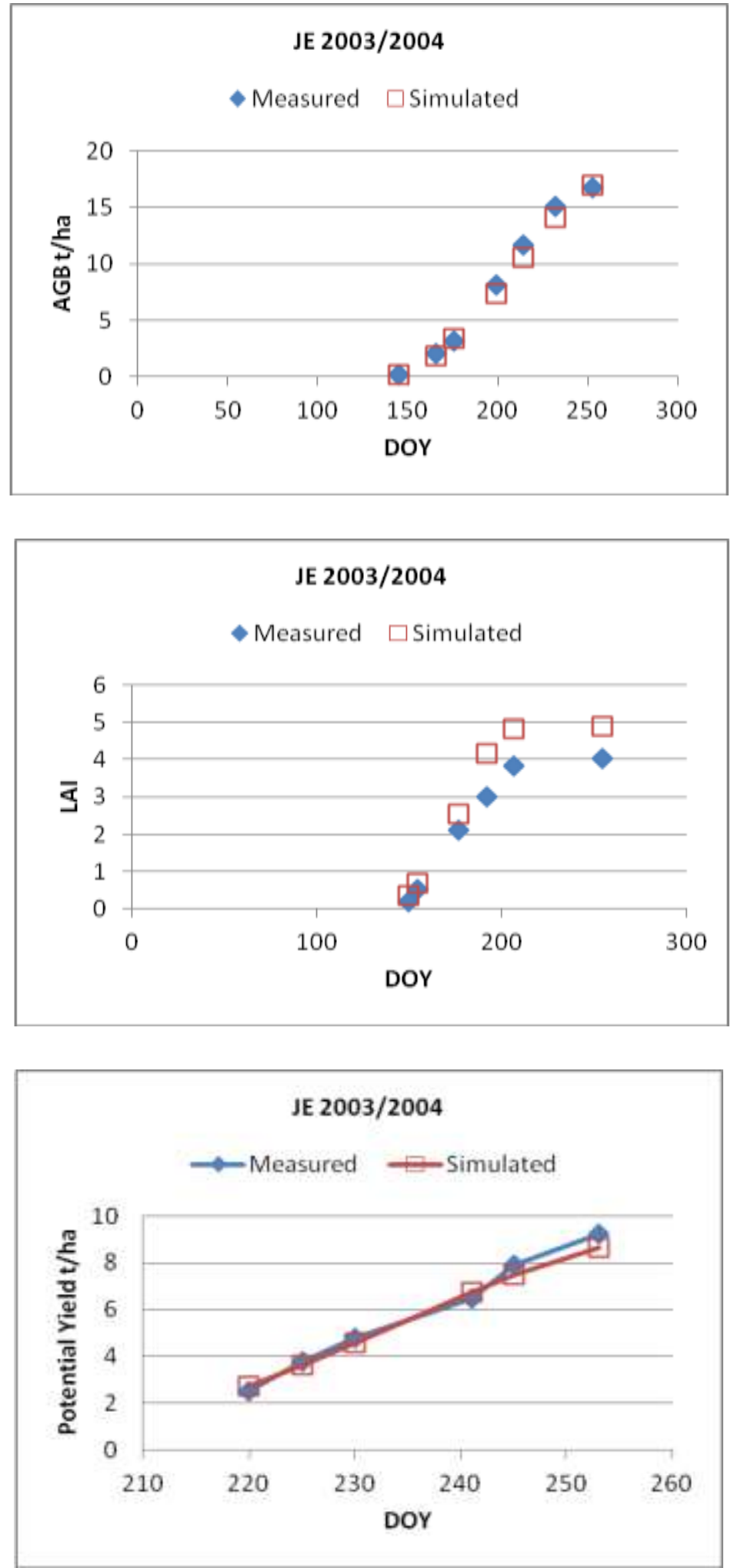

Fig. 1. Measured and simulated AGB, LAI and Potential Yield (t/ha) values after Calibration. JE: Japonica early (Giza 177), DOY (Days of Year) 

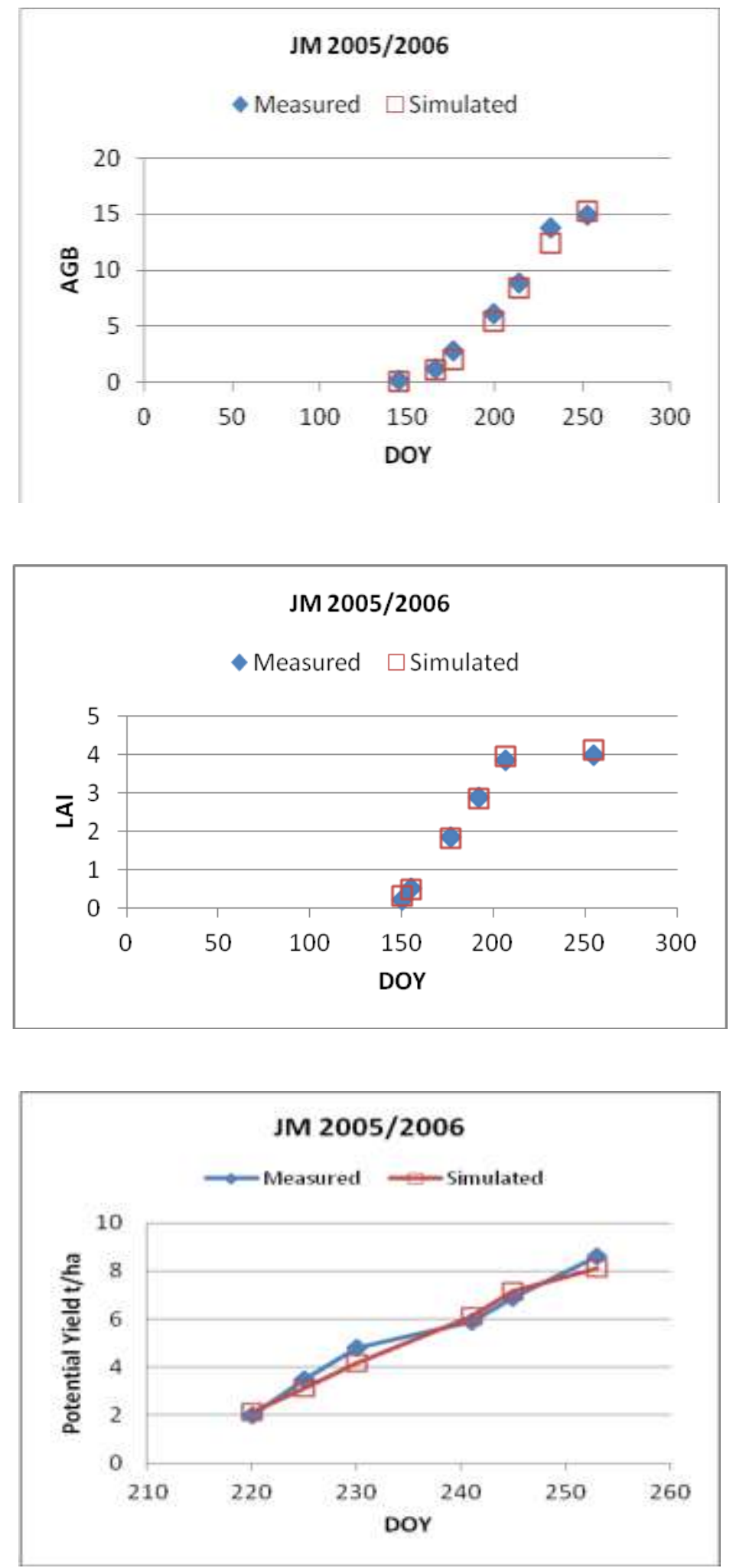

Fig. 2. Measured and simulated AGB, LAI and Potential Yield (t/ha) values after Calibration. JM: Japonica medium -late (Sakha 101), DOY (Days of Year) 
Table 4. Indices of agreement between observed and simulated aboveground biomass (AGB; $\mathrm{t} / \mathrm{ha}$ ), leaf area index $\left(\mathrm{LAI} ; \mathrm{m}^{2} / \mathrm{m}^{2}\right)$ and Potential Yield (t/ha) values

\begin{tabular}{|c|c|c|c|c|c|c|c|c|c|c|}
\hline Activity & $\begin{array}{l}\text { Variety } \\
\text { group }\end{array}$ & Year & Variable & $\begin{array}{c}\text { RRMS } \\
\% \\
\end{array}$ & $\mathbf{E F}$ & CRM & CD & Slope & $\begin{array}{c}\text { Intercept } \\
\text { (t/ha) }\end{array}$ & $\mathbf{R}^{2}$ \\
\hline \multirow{6}{*}{ Calibration } & \multirow{3}{*}{$\begin{array}{c}\text { JE } \\
(\text { Giza 177) }\end{array}$} & \multirow{3}{*}{$\begin{array}{l}2003 \\
2004\end{array}$} & AGB & 57 & 0.99 & 0.05 & 1.07 & 1.03 & 0.13 & 0.99 \\
\hline & & & LAI & 64 & 0.75 & -0.27 & 0.58 & 0.80 & -0.04 & 0.99 \\
\hline & & & $\begin{array}{c}\text { Potential } \\
\text { yield }\end{array}$ & 33 & 0.98 & 0.02 & 1.18 & 1.08 & -0.33 & 0.99 \\
\hline & \multirow{3}{*}{$\begin{array}{c}\text { JM } \\
\text { (Sakha101) }\end{array}$} & \multirow{3}{*}{$\begin{array}{l}2005 \\
2006\end{array}$} & AGB & 20 & 0.98 & 0.07 & 1.01 & 1.00 & 0.43 & 0.99 \\
\hline & & & LAI & 7 & 1.00 & -0.02 & 0.97 & 0.99 & 0.00 & 1.00 \\
\hline & & & $\begin{array}{c}\text { Potential } \\
\text { yield }\end{array}$ & 39 & 0.97 & 0.03 & 1.00 & 0.99 & 0.19 & 0.97 \\
\hline \multirow{6}{*}{ Evaluation } & \multirow{3}{*}{$\begin{array}{c}\text { JE } \\
(\text { Giza 177) }\end{array}$} & \multirow{3}{*}{$\begin{array}{l}2009 \\
2010\end{array}$} & AGB & 10 & 0.97 & -0.08 & 1.03 & 1.01 & -0.76 & 0.98 \\
\hline & & & LAI & 49 & 0.85 & -0.18 & 0.85 & 0.94 & -0.31 & 0.96 \\
\hline & & & $\begin{array}{c}\text { Potential } \\
\text { yield }\end{array}$ & 30 & 0.98 & 0.00 & 1.32 & 1.15 & -0.86 & 1.00 \\
\hline & \multirow{3}{*}{$\begin{array}{c}\text { JM } \\
\text { (Sakha101) }\end{array}$} & \multirow{3}{*}{$\begin{array}{l}2011 \\
2012\end{array}$} & $\mathrm{AGB}$ & 69 & 0.98 & 0.08 & 1.03 & 1.02 & 0.52 & 1.00 \\
\hline & & & LAI & 35 & 0.91 & -0.02 & 0.80 & 0.87 & 0.31 & 0.94 \\
\hline & & & $\begin{array}{c}\text { Potential } \\
\text { yield }\end{array}$ & 65 & 0.93 & -0.03 & 1.40 & 1.16 & -1.06 & 0.95 \\
\hline
\end{tabular}

(RRMSE) Relative Root Mean Square Error (\%, 0 to $+\infty$, optimum $=0$ ).

(EF) Modelling Efficiency (,$--\infty$ to 1 , optimum $=1)$.

(CRM) Coefficient of Residual Mass $(-,-\infty$ to 1 , optimum $=0)$.

$(C D)$ coefficient of determination (minimum $=0$, optimum $=1$ ).

\section{Evaluation of crop model parameters}

Figures $(3,4)$ and Table (4) show the results of the crop parameter test. Despite a general slight overestimation, for both varieties, WARM satisfactory simulates aboveground biomass values, also during the evaluation. As already discussed for the calibration phase, the best values of fitting indices were calculated for the medium- late variety.

Measured aboveground biomass values are accurately reproduced by the model. In all cases, $\mathrm{R}^{2}$ is higher than 0.98 for both varieties. The modeling efficiency for the simulation of leaf area index reached a value of 0.85 and 0.91 for Giza 177 and Sakha 101, respectively. Index of agreement between predicted and observed values fluctuated from 0.90 to 0.98 (a value of 1.0 indicating excellent agreement), respectively with most values equal or better than 0.95 .

Simulated values of potential yield for both varieties present a good agreement with measured ones after evaluation, with the modeling efficiency (EF) constantly above 0.90 . While, the RRMSE was $30 \%$ and $65 \%$ for Giza 177 and Sakha 101, respectively. (CD), (CRM) and $\mathrm{R}^{2}$ for both varieties are closer to their optimum.
It is important to underline that WARM performances in evaluation are better than the calibration ones: average values of relative root mean square error (RRMSE), modeling efficiency (EF), coefficient of residual mass $(\mathrm{CRM})$ and $\mathrm{R}^{2}$ for the evaluation datasets are closer to their optimum.

During the evaluation, the model presented the same level of accuracy discussed for the calibration dataset. The fitting indices calculated for the JE variety are better than those calculated for the other variety group. Also during the evaluation, the model has shown to be able to reproduce growth and development of different varieties under different conditions.

The WARM approach to growth modelling can be considered more representative of paddy rice systems and more parsimonious with respect to parameter needs. The approach used to simulate air temperature is an example of the closer representation of the real system. The different processes influencing crop growth were implemented in WARM by maintaining a certain balance among the model compartments as cited by (Confalonieri et al., 2009). 

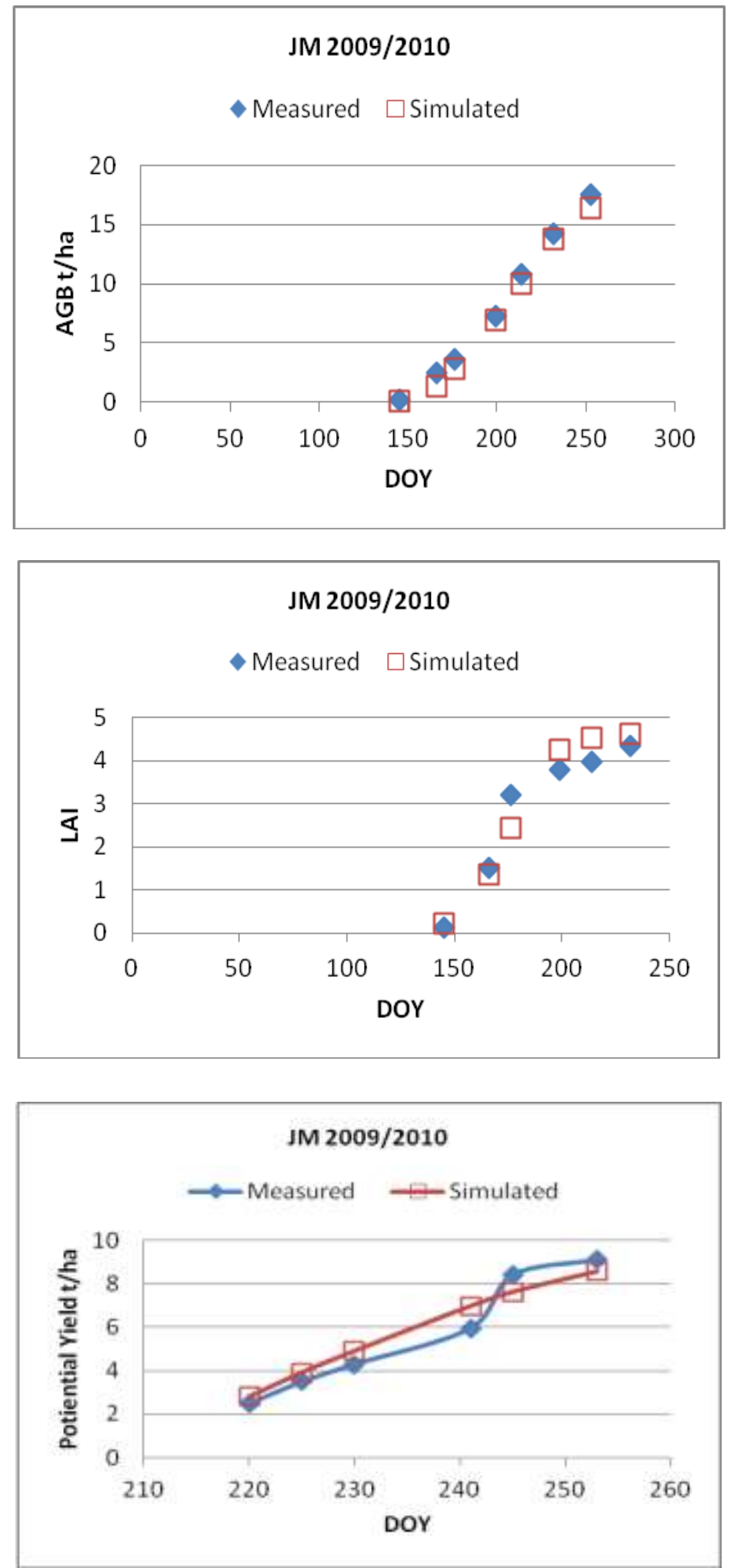

Fig 3. Measured and simulated AGB, LAI and Potential Yield (t/ha) values after Evaluation. JM: Japonica medium -late (Sakha 101), DOY (Days of Year) 

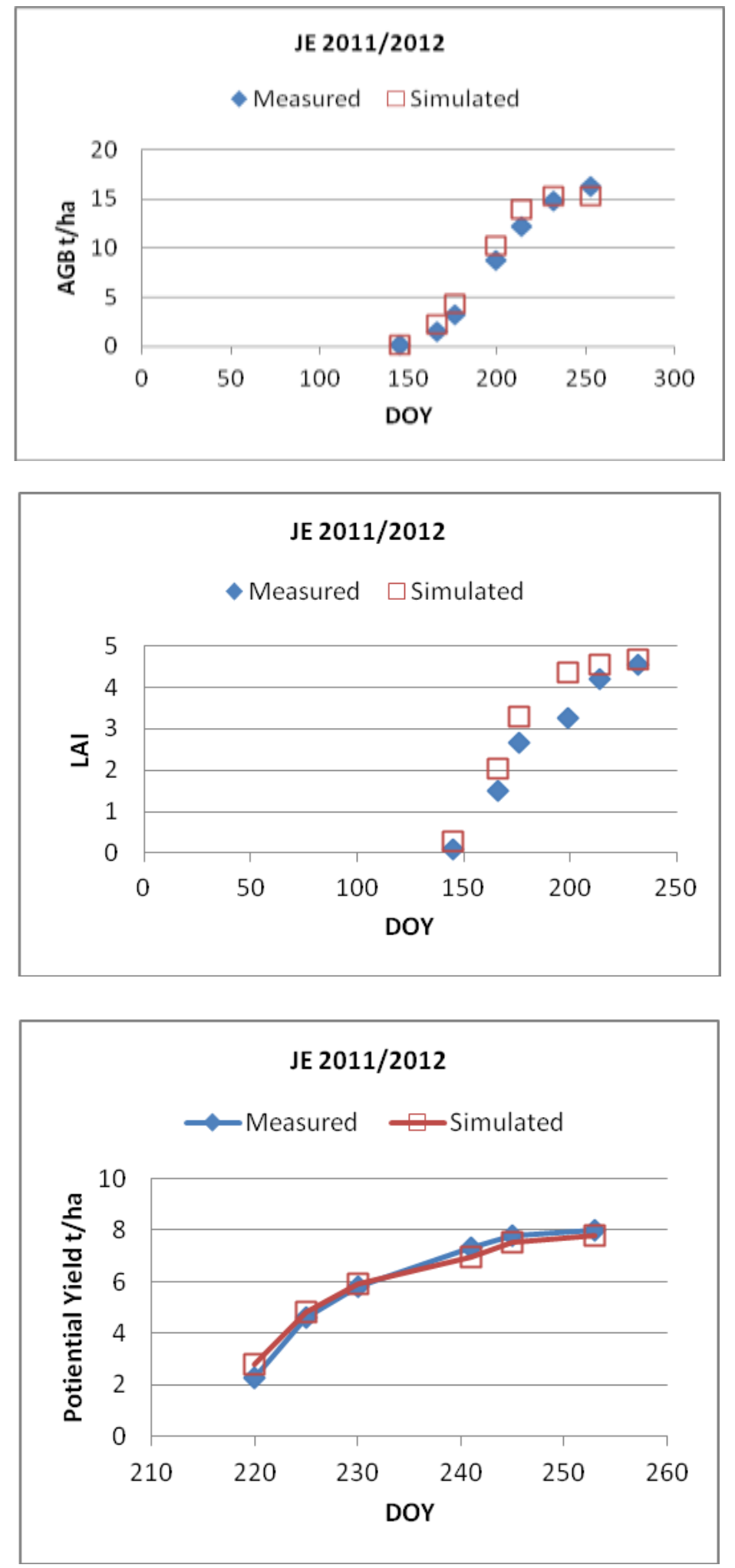

Fig 4. Measured and simulated AGB, LAI and Potential Yield (t/ha) values after Evaluation. JE: Japonica early (Giza 177), DOY (Days of Year) 


\section{CONCLUSIONS}

The aim of this work s was to calibrate and evaluate the WARM model for simulating rice crop in Egypt to forecast yield, and to assess the likely impact of climate change on rice yield.

After calibration and evaluation, model performances are very similar and the simulation of floodwater effect on temperature did not lead to incoherent model behaviors. These results show that the model is robust and able to reproduce yield variability within years and locations.

This is the first time a model explicitly accounting for the micrometeorological peculiarities of paddy rice has been evaluated. The WARM model can be considered suitable for investigating the interactions between weather and crop productivity in a changing climate.

WARM, after this parameterization, is able to simulate accurately the growth of both rice cultivars types (Giza 177 and Sakha 101). The exploration of different meteorological conditions allows to exclude that the presented parameters sets include errors due to particular meteorological situations. Therefore, the two parameters sets calibrated for Japonica early and medium-late varieties may be used for large-scale simulations of rice growth in Egypt for carrying out operational rice yield forecasts on regional, national and international scales, aiming at managing food security problems.

\section{ACKNOWLEDGMENTS}

I gratefully acknowledge the contribution of Dr. Simone Bregaglio (Department of Agriculture and Environmental Sciences-Production, Landscape, Agroenergy, University of Milan) for the help provided in interpreting the results of this study. Prof. Roberto Confalonieri (European Commission, Joint Research Centre, Institute for the Protection and Security of the Citizen) is also acknowledged for valuable comments and suggestions.

Special thanks also to the (Department of Crop Science, Section of Agronomy, University of Milan) for hosting me during my postdoctoral fellowship period at University of Milan.

\section{REFERENCES}

Anastacio, P.M., Frias, A.F. and Marques, J.C., 1999. CRISP (crayfish and rice integrated system of production): 1. Modelling rice (Oryza sativa L.) growth and production. Ecol. Model. 123, 17-28.
Bachelet, D., Gay and C.A., 1993. The impacts of climate change on rice yield: a comparison of four model performances. Ecol. Model. 65, 71-93.

Boschetti M., Bocchi S., Stroppiana D. and Brivio P.A. (2006) Estimation of parameters describing morpho-physiological features of Mediterranean rice group for crop modelling purposes, Ital. J. Agrometeorol. 3, 17-25.

Bouman B.A.M., Xiaoguang Y., Huaqi W., Zhimin W., Junfang Z. and Bin C. (2006) Performance of aerobic rice varieties under irrigated conditions in North China, Field Crop. Res. 97, 53-65.

Casanova D., Epema G.F. and Goudriaan J. (1998) Monitoring rice reflectance at field level for estimating biomass and LAI, Field Crop. Res. 55, 83-92.

Cassman, K.G., Peng, A., Dobermann, A. and 1997. Nutritional physiology of the rice plants and productivity decline of irrigated rice systems in the tropics. Soil Sci. Plant Nutr. 43, 1101-1106.

Confalonieri R., Acutis M., Bellocchi G., Cerrani I., Tarantola S., Donatelli M. and Genovese G. (2006a) Exploratory sensitivity analysis of CropSyst,WARMandWOFOST: a case-study with rice biomass simulations, Ital. J. Agrometeorol. 3, 17-25.

Confalonieri R. and Bocchi S. (2005) Evaluation of CropSyst for simulating the yield of flooded rice in northern Italy, Eur. J. Agron. 23, 315- 326.

Confalonieri R., Gusberti G., Bocchi S. and AcutisM. (2006b) The CropSyst model to simulate the $\mathrm{N}$ balance of rice for alternative management, Agron. Sustain. Dev. 26, 241249

Confalonieri R., Mariani L. and Bocchi S. (2005) Analysis and modelling of water and near water temperatures in flooded rice (Oryza sativa L.), Ecol. Model. 183, 269280.

Confalonieri R., Rosenmund A.S. and Baruth B. (2009). An improved model to simulate rice yield. Agron. Sustain. Dev. 29:463-474

Confalonieri, R., 2005.GAIA: a new model for the simulation of plant growth. Internal Report, Joint Research Centre of the European Commission, Ispra.

Day,W., 2001. Modelling crop physiology for integrated decision making. Ann. Appl. Biol. 138, 215-219.

Dingkuhn M., Johnson D.E., Sow A. and Audebert A.Y. (1999) Relationships between upland rice canopy characteristics and weed competitiveness, Field Crop. Res. 61, 79-95.

Dingkuhn M., Jones M.P., Johnson D.E. and Sow A. (1998) Growth and yield potential of Oryza sativa and $O$. glaberrima upland rice cultivars and their interspecific progenies, Field Crop. Res. 57, 57-69.

Dingkuhn, M., Sow, A., Samb, A., Diack, S. and Asch, F., (1995). Climatic determinants of irrigated rice performance in the Sahel - I. Photothermal and microclimatic responses of flowering. Agr. Syst. 48, 385410. 
Kiniry, J.R., Jones, C.A., O’Toole, J.C., Blanchet, R., Cabelguenne, M., Spanel and D.A., 1989. Radiation-useefficiency in biomass accumulation prior to grain filling for five grain crop species. Field Crops Res. 20, 51-64.

Kropff M.J., van Laar H.H. and Matthews R.B. (1994) ORYZA1: An ecophysiological model for irrigated rice production SARP Research Proceedings, International Rice Research Institute: Los Banos, Philippines, 110 p.

Lancashire, P.D.; Bleiholder H, Langeluddecke P., Stauss R., van den Boom T., Weber E. and Witzen-Berger A. (1991). "An uniform decimal code for growth stages of crops and weeds". Ann. Appl. Biol. 119 (3): 561-601.

Loague, K.M. and Green, R.E., 1991. Statistical and graphical methods for evaluating solute transport models: overview and application. J. Contam. Hydrol. 7, 51-73.

Mae, T., 1997. Physiological nitrogen efficiency in rice: nitrogen utilization, photosynthesis, and yield potential. Plant Soil 196, 201-210.

Mahmood, R., 1998. Air temperature variations and rice productivity in Bangladesh: as comparative study of the performance of the YIELD and the CERES-Rice models. Ecol. Model. 106, 201-212.
Mall R.K. and Aggarwal P.K. (2002) Climate change and rice yields in diverse agro-environments of India. I. Evaluation of impact assessment models, Climatic Change 52, 315330.

Nishiyama, I., 1995. Damage due to extreme temperatures. In: Matsuo, T., Kumazawa, K., Ishii, R., Ishihara, K., Hirata, H. (Eds.), Science of the Rice Plant, vol. 2. Physiology, Food and Agriculture Policy Research Center, Tokyo, pp. 769-800.

RRTC 2003-2011; Rice research and training center, Annual Reports 2003-2011,Sakha Kafelsheikh, Egypt.

Sié M., Dingkuhn M., Wopereis M.C.S. and Miezan K.M. (1998) Rice crop duration and leaf appearance rate in a variable thermal environment. I. Development of an empirically based model, Field Crop. Res. 57, 1-13.

Singh U., Ritchie J.T. and Godwin D.C. (1993) A user's guide to CERES Rice - v2.10. International Fertilizer Development Center: Muscle Shoals, AL, USA.

Wit A.J.W., Boogaard H.L. and Van Diepen C.A. (2005) Spatial resolution of precipitation and radiation: The effect on regional crop yield forecasts, Agr. Forest Meteorol. $135,156-168$. 


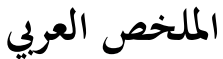

\section{تقييم نموذج WARM لمحاكاة بعض اصناف محصول الأرز في ثمال الدلتا}

شيماء عبد العظيم الطنطاوى بدوى

نبات الأرز علي صنفي الأرز جيزة 177،سخا 101 وذلك لتقدير بعض المتغيرات والمعلومات المامة للأرز مثل الكتلة الحيوية فوق سطح الأرض، دليل مساحة الورقة، طاقة المحصول، مساحة الورقة المحددة وتاريخ المراحل الرئيسية من حياة النبات. أظهرت النتائج أن النموذج المتبع ذو كفاءة عالية في إعادة إنتاج ومحاكاة نمو محصول الأرز لكلا الصنفين. أظهر تقييم كفاءة أداء النموذج، أن الجذر النسبي لمتوسط مربع

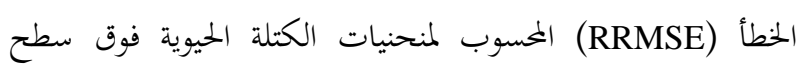
الأرض كانت تفوق 50\% لمجموعة المعايرة، 30\% ملمجوعة التقييم. كذلك أظهرت كفاءة النموذج(EF) قيم دائما موجبة وكان معامل

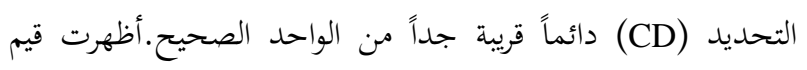

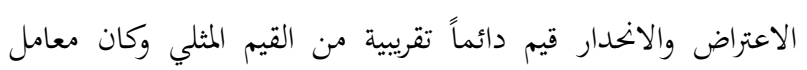

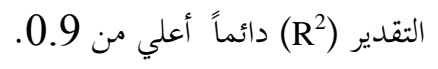

سجلت القيم القياسية للتوافق والمحسوبة لمجموعات التقييم أفضل

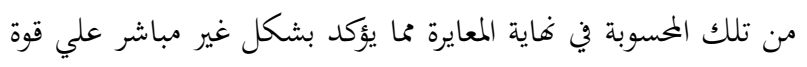

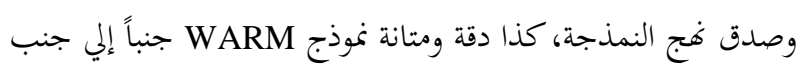
مع متطلبات منخفضة من حيث المدخلات وتطبيق وحدات إعادة

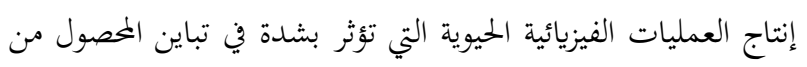
سنة إلي أخري وجعل هذا النموذج مناسب للتنبؤ بمحصول الأرز علي النطاق الإقليمي والقومي والدولي.
أجريت هذه الدراسة في جامعة ميلانو، ايطاليا خلال عام

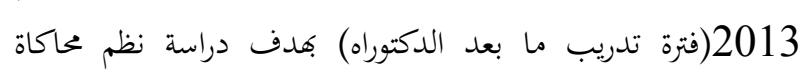

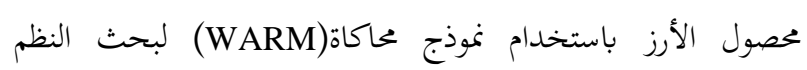

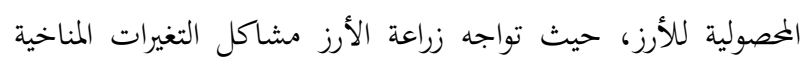

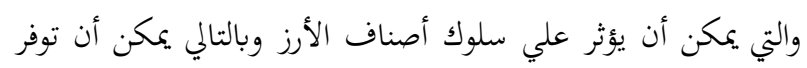
نماذج المحاكاة الديناميكية أداة مفيدة لتحليل النظم اللازمة لتحسين

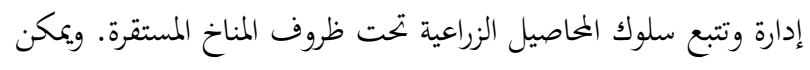
تطبيق نموذج محاكاه (WARM) للأرز المروى على الأرز الجاف.

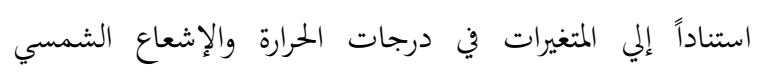
و تأثيرها علي نمو مصول الأرز والإنتاجية، يحاكي أيضاً تقييم الكتلة الحيوية، تأثيرات مياه الري علي درجات الحرارة وانعكاسها علي الكتلة الحيوية وعقم السنيبلات وكذا إدارة مياه الري والمواد الكيماوية وهيدرولوجيا التربة.

قيمت تقديرات الكتلة الحيوية باستخدام نظام WARM بمنطقة سخا بكفر الشيخ وقد تم جمع البيانات التي تعمل على تطبيق نظام

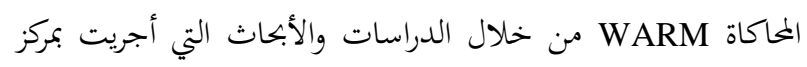
بحوث الأرز بسخا ونشر بعضها فن ورش العمل والمؤتمرات خلال الفترة

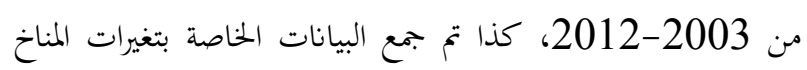

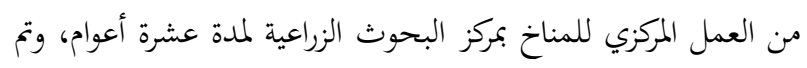

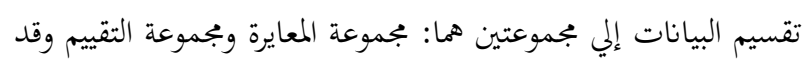

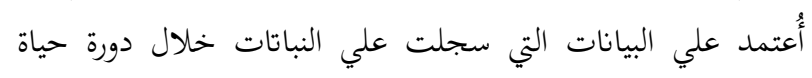

